\title{
Assessing microstructures of pyrrhotites in basalts by multifractal analysis
}

\author{
S. Xie ${ }^{1,2,3}$, Q. Cheng ${ }^{1,3}$, S. Zhang ${ }^{1,4}$, and K. Huang ${ }^{2}$ \\ ${ }^{1}$ State Key Laboratory of Geological Processes and Mineral Resources (GPMR), China University of Geosciences (CUG), \\ Wuhan, 430074, China \\ ${ }^{2}$ Earth Science Faculty, China University of Geosciences (CUG), Wuhan, 430074, China \\ ${ }^{3}$ Department of Earth and Space Science and Engineering, York University, Toronto, ON, M3J 1P3, Canada \\ ${ }^{4}$ Institute of Resources and Environment, Shijiazhuang University of Economics, Hebei, 050031, China
}

Received: 25 March 2010 - Revised: 28 June 2010 - Accepted: 29 June 2010 - Published: 19 July 2010

\begin{abstract}
Understanding and describing spatial arrangements of mineral particles and determining the mineral distribution structure are important to model the rock-forming process. Geometric properties of individual mineral particles can be estimated from thin sections, and different models have been proposed to quantify the spatial complexity of mineral arrangement. The Gejiu tin-polymetallic oreforming district, located in Yunnan province, southwestern China, is chosen as the study area. The aim of this paper is to apply fractal and multifractal analysis to quantify distribution patterns of pyrrhotite particles from twentyeight binary images obtained from seven basalt segments and then to discern the possible petrological formation environments of the basalts based on concentrations of trace elements. The areas and perimeters of pyrrhotite particles were measured for each image. Perimeter-area fractal analysis shows that the perimeter and area of pyrrhotite particles follow a power-law relationship, which implies the scaleinvariance of the shapes of the pyrrhotites. Furthermore, the spatial variation of the pyrrhotite particles in space was characterized by multifractal analysis using the method of moments. The results show that the average values of the area-perimeter exponent $\left(D_{A P}\right)$, the width of the multifractal spectra $\left(\Delta(D(0)-D(2))\right.$ and $\left.\Delta\left(D\left(q_{\min }\right)-D\left(q_{\max }\right)\right)\right)$ and the multifractality index $\left(\tau^{\prime \prime}(1)\right)$ for the pyrrhotite particles reach their minimum in the second basalt segment, which implies that the spatial arrangement of pyrrhotite particles in Segment 2 is less heterogeneous. Geochemical trace element analysis results distinguish the second basalt segment sample from other basalt samples. In this aspect, the frac-
\end{abstract}

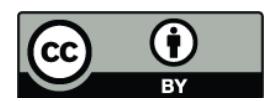

Correspondence to: $\mathrm{S}$. Xie (tinaxie2006@gmail.com) tal and multifractal analysis may provide new insights into the quantitative assessment of mineral microstructures which may be closely associated with the petrogenesis as shown by the bulk-rock geochemical analysis.

\section{Introduction}

In nature, many objects can be viewed as random twocomponent systems. For example, sedimentary rocks are composed of pore and solid components. Soil systems also can be separated into pores and solid particles. Correspondingly, image analytical techniques (Gerard, 1992; Flavior et al., 1998) have been extensively used to recognize and separate these two components. Since the concept of fractal emerged (Mandelbrot, 1977), various fractal and multifractal models have been proposed to characterize the spatial variety of different patterns for pore and solid components in both sedimentary rocks (Muller and McCauley, 1992; McCauley, 1992; Muller et al., 1995; Muller, 1996; Xie et al., 2010a; Kron, 1986) and soils (Bird et al., 2006; Pachepsky et al., 2000; Perrier et al., 1999).

Rocks are composed of different mineral particles with different shapes, sizes, and volumes (Wadell, 1932). Size, shape, and spatial arrangement of minerals have been used to classify rock texture. In addition to mineral compositions, particle sizes and shapes, textural identification and interpretation for rocks and associated minerals are tools necessary for understanding the processes involved in the genesis of rocks, which in turn is very important for understanding the formation of minerals and their structures. The selection and interpretation of morphological parameters are also helpful for quantitative assessments. 
Generally, metallic ore-bearing rocks are composed of ore minerals and gangue minerals. Ore minerals usually refer to the utilizable metallic or non-metallic minerals within ores, such as chromites in chromium ores, chalcopyrrhotites and bornites in copper ores, and asbestos in asbestine ores as well. Gangue minerals, called as useless minerals, often refer to materials so intimately associated with ore that it has to be mined with, and later removed by various crushing, grinding and separation processes. In such a sense, ores can also be separated into two components in a two-dimensional space, one is the solid gangue mineral component and the other is the metallic mineral component. Thus, binary image techniques can also be used to recognize these two parts and the mineral structures can be characterized by different statistical methods as well. By Number-Area (N-A) model, Perimeter-Area (P-A) model, box-counting fractal model and multifractal models, the microstructures of rocks and ores during deformation and replacement have been studied and the complexity and irregularity of minerals shown by the fractal and multifractal dimensions provide information on mineral genesis (Wang, 2008). With the discrete multifractal technique, Wang (2008) explored the transfer relationship between the sphalerite and carbonate particles across the sphalerite band structure during growth by Markov Chain model. Box-counting dimensions, generalized fractal dimensions and multifractal spectra have been calculated to characterize the spatial structure of the pyrites in two ore-bearing skarn samples and then to discuss the link between the multifractal parameters and the ore-forming potentials of the rocks under consideration (Xie et al., 2009). The generalized PA model in combination with cumulative N-A fractal model and shape indexes are also used to distinguish between cassiterites of different phases in tin-deposits (Zuo et al., 2009).

In this paper, we consider twenty-eight binary images of thin sections from seven ore-bearing basalt segments, and analyze the spatial distribution patterns of pyrrhotite minerals in the basalts by parameter-area (P-A) model and multifractal analysis using the method of moments. On the other hand, we demonstrate how multifractal distribution patterns of metallic minerals could be correlated with the petrogenic processes of the basalts together with the geochemical bulkrock trace element analysis.

\section{Geological background}

The study area is the Gejiu tin district located in the southeast of Yunnan province. The Gejiu super-large Tinpolymetallic deposit in the eastern Gejiu area is an important tin-dominated ore concentration center and has more than 20 kinds of other nonferrous and rare metal resources, such as $\mathrm{Cu}, \mathrm{Pb}, \mathrm{Zn}, \mathrm{W}, \mathrm{Ag}, \mathrm{Bi}$, In, and so on. Because of the complex geological settings and abundant mineral resources, Gejiu area has attracted international extensive interests in recent decades (Yu et al., 1988; Chen, 2007). Gejiu tin-polymetallic ore deposit has the characteristics of typical volcano-sedimentary ore deposits (Li et al., 2006).

The volcanic activities mainly occurred during three stages in the Middle Triassic period, including Anisian stage, Ladinian stage and Norian stage. By and large, the basalts of Anisian stage distribute extensively in the eastern Gejiu area, whereas the basalts of Ladinian stage and Norian stage are in western Gejiu area. The Anisian basalts in Gejiu formation of the first section $\left(T_{2} g^{1}\right)$ mainly occurred in layers among the carbonates of the same strata. The basalt rock mass conformably contacts each other. Some folds are present along the contact lines. It is reported that the Anisian basalt played an important role in the formation of Gejiu tin-polymetallic ore deposits ( $\mathrm{Li}$ et al., 2007). The Anisian basalts were successively present in Qibeishan, Laochang and Gejiu tincopper polymetallic deposit, and the genesis of these basalts from different segments has been debated. In Gejiu tincopper deposit, the Anisian basalts, which are weakly orebearing, were present in seven segments underground. Table 1 shows the outcrop depths of these basalts in different segments. In this work, eight samples were continuously collected. As shown in Table 1, two samples were from the second segment and one sample per segment from the other six segments.

For all the basalt samples, polished sections were made (as listed in Table 1), microscopic examination was conducted, and metallic minerals were observed. All the samples are biotite tremolitic basalts. It is found that, besides a small amount of pyrites and chalcopyrites, the major metallic minerals are pyrrhotites which amount to $10-20 \mathrm{wt} \%$.

All the eight basalt samples were sent to the state key lab of Geological Processes and Mineral Resources at China University of Geosciences to measure the concentrations of 37 trace elements using laser ablation-inductively coupled plasma-mass spectrometry (LA-ICP-MS). Detailed operating conditions for the laser ablation system and the ICPMS instrument and data reduction can be refereed to Liu et al. (2008). However, due to the high concentrations of $\mathrm{Pb}$ and some associated elements, which may affect the stability of the instrument, only those data from five basalt samples were reported (Table 1). The five samples include Sample 201-3 and Sample 201-4 from the second basalt segment, and Sample 201-9, 201-10 and 201-11 from the fifth, sixth and seventh basalt segment, respectively.

\section{Image processing}

Four representative views for each polished thin section in Table 1 were chosen to acquire digital images, and photomicrographs were taken to show the pyrrhotite aggregates (Fig. 1a) under the Environmental Scanning Electron Microscope (ESEM) in the state key lab of Geological Processes and Mineral Resources in China. Digital image processing was completed with the aid of GIS (Geographical 

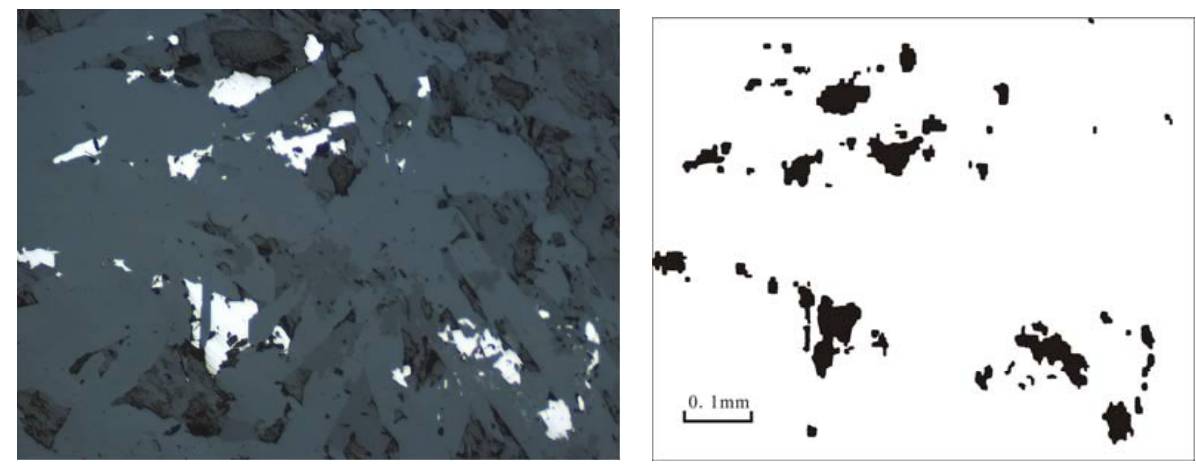

Fig. 1. (a) The digital image of the sample from the second basalt segment under the Environmental Scanning Electron Microscope (ESEM). (b) Rock binary image, the pyrrhotite particle with black pixels and the gangue mineral in white. This figure only extracts the major pyrrhotite particles from the ESEM image in (a) in order to eliminate the distortion by the magnification scale. And used for calculation in the paper are the pyrrhotite particles shown as the black pixels.

Table 1. Basic information about the samples used for analysis.

\begin{tabular}{lllllllll}
\hline Basalt Segment & 1 & \multicolumn{2}{c}{2} & 3 & 4 & 5 & 6 & 7 \\
\hline Depth underground (m) & $432.77-446.89$ & $448.89-466.82$ & $467.82-473.97$ & $489.45-491.70$ & $493.17-496.67$ & $498.42-500.67$ & $503.74-512.19$ \\
Sample Label & $201-1$ & $201-3$ & $201-4$ & $201-5$ & $201-6$ & $201-9$ & $201-10$ & $201-11$ \\
Polished section & $\sqrt{ }$ & $\sqrt{ }$ & $\sqrt{ }$ & $\sqrt{ }$ & $\sqrt{ }$ & $\sqrt{ }$ & $\sqrt{ }$ & $\sqrt{ }$ \\
Trace element analysis & & $\sqrt{ }$ & $\sqrt{ }$ & & & $\sqrt{ }$ & $\sqrt{ }$ & $\sqrt{ }$ \\
\hline
\end{tabular}

Information System) techniques. The pyrrhotite image of the samples from Segment 2 is used here as an example to introduce the steps of image processing. The pyrrhotite photomicrograph was taken using plane reflected light, digitized as a 256-grey scale black-white image (Fig. 1a), and then converted into a binary image according to the grey scales (Fig. 1b). Repeated empirical experiments have indicated that the outlines with 120-grey scale are adequate to separate pyrrhotite aggregates from gangue minerals. Other metallic particles, such as sphalerites and chalcopyrites which are too few and sparse, are not included in the calculation. The perimeters and the coverage spaces of these extracted pyrrhotite particles can be readily detected. Some quite small separate particles unrelated to pyrrhotite aggregates have been deleted and removed. It can reasonably approximate the extracted outline of the pyrrhotite aggregates, as shown in Fig. 1b. Likewise, other images were processed with the same steps and then further calculation and analysis can be performed.

\section{Fractal and multifractal analysis}

\subsection{P-A fractal analysis}

The Perimeter-area (P-A) model, or island-arcs model, was firstly put forward by Mandelbrot (Mandelbrot, 1977, 1983). It relates the perimeters and areas within a set of irregular self-similar geometrical shapes. The P-A model was used to analyze the geometry of cloud areas and characterize the degree of complexity of the cloud shapes (Lovejoy, 1982). A general form of P-A was proposed and originally applied for characterizing copper porphyry alteration zones with both irregular areas and perimeters (Cheng et al., 1994). This modified model has been also applied to characterize the distributions of trace elements in minerals (Zhang et al., 2001) and shapes for minerals (Wang et al., 2005; Wang, 2008; Zuo et al., 2009).

The original form of P-A proposed by Mandelbrot (Mandelbrot, 1977, 1983) was

$P \propto A^{\frac{1}{2} D_{P}}$

where $D_{p}$ is the fractal dimension of perimeter $P$. It was found that this model is only valid for regular areas but not for fractal areas. For fractal areas the more general form was proposed by Cheng et al. (1994):

$P \propto A^{\frac{1}{2} D_{A P}}$,

where $P$ is the perimeter and $A$ is the area of one pyrrhotite particle in the thin section, " $\propto$ " means "proportional to", and $D_{A P}=D_{P} / D_{A}$ is the ratio of the fractal dimension of perimeter $D_{P}$ over the fractal dimension of area $D_{A}$. It can be seen that only if the area is a normal area with dimension 2 , then $D_{A P}=D_{P}$, accordingly the general form becomes the original one. More discussions about the new model are refereed to Cheng (1995). 


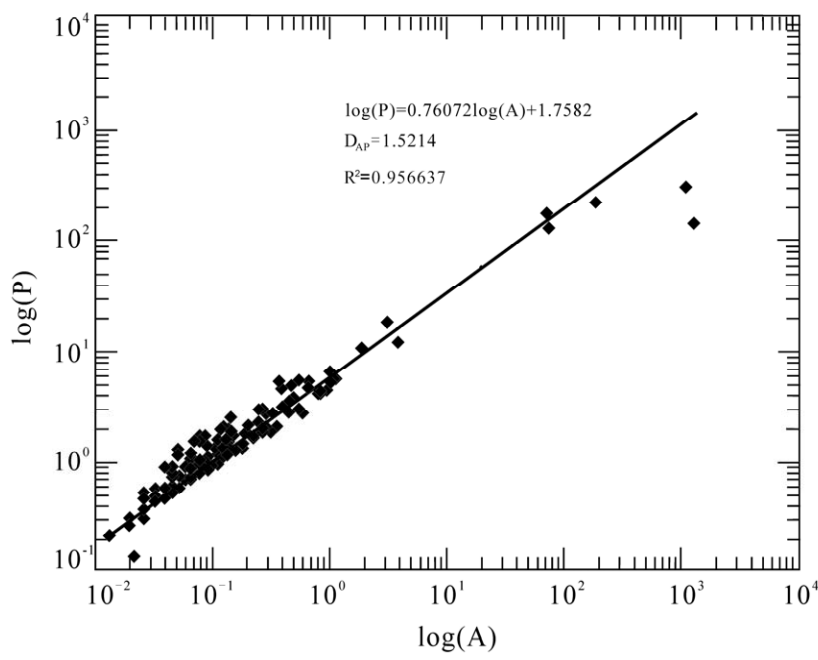

Fig. 2. P-A analysis results of the pyrrhotite particles from Segment 6 .

On $\log -\log$ plots, the data of $P$ and $A$ can be plotted and the linear relationship between them can be shown. Then the area-perimeter exponent $D_{A P}$ can be calculated by fitting a straight line using the least-squares method. The slope of the $\mathrm{P}$-A line can be estimated with the value of $1 / 2 D_{A P}$ according to Eq. (2). Usually, $D_{A P}$ ranges from 1 to 2 .

The image in Fig. 1b is applied to measure the perimeters and areas of the pyrrhotite particles under MapGIS, a GIS software platform developed by China University of Geosciences. According to Eq. (2), the values of the perimeters and the areas are plotted in the log-log diagram (shown in Fig. 2) and these dots can be fitted with a straight line. Consequently, the $D_{A P}$ value can be calculated based on the slope of the fitted straight line. All the $D_{A P}$ values have been obtained for the 28 digital images and all the average $D_{A P}$ values from different segments are listed in Table 2.

Table 2 shows that all the $D_{A P}$ values are ranging from 1 to 2, which implies the irregularity of the metallic pyrrhotite particles at the microscale levels. The average $D_{A P}$ value for Segment 2 is 1.25 and reaches a minimum, while the other average $D_{A P}$ values greater than 1.3 . This may imply that the shapes of the pyrrhotite particles in Segment 2 are less irregular.

\subsection{Multifractal analysis}

In this study, we also compute multifractal dimensions. In terms of multifractal analysis, similarly to pore structure analysis for soil pore systems (Bird et al., 2006) and carbonate pore systems (Xie et al., 2010a), we define here a measure associated with the metallic particles of the digital images. There are some other examples involving definition of binary pattern as multifractal measures such as fractures (Agterberg et al., 1996), alteration zones, rocks, and so on. Simply, a grid box with size $\delta$ can be made to superimpose over the part of the metallic mineral spaces (the black pixels as shown in Fig. 1b) in the studied images. Supposed that a grid box contains $m_{i}$ pixels, where $m_{i}$ takes a value from 1 to $\delta \times \delta$. Then the measure, denoted herein by $\mu_{i}(\delta)$, of the $i$ th box covering the metallic pyrrhotite particles, is defined as $m_{i} / M$, where $\mathrm{M}$ is the total number of pyrrhotite particle pixels in the image. Thus, a partition function, $\chi_{q}(\delta)$, with the moment $q$ of $\mu_{i}(\delta)$ can be constructed as the following equation (Halsey, 1986; Bird et al., 2006):

$\chi_{q}(\delta)=\sum_{i=1}^{n(\delta)}\left(\mu_{i}\right)^{q}=\sum_{i=1}^{n(\delta)}\left(\frac{m_{i}}{M}\right)^{q}=\sum_{j=1}^{\delta \times \delta} N_{j}\left(\frac{j}{M}\right)^{q}$,

where $n(\delta)$ is the number of small boxes covering the metallic particle pixels, and $N_{j}$ is the number of boxes containing $j$ pixels. The sum in Eq. (3) can be calculated over all the boxes.

In this way, there exists the power-law relationship between the partition function $\chi_{q}(\delta)$ and the box size $\delta$,

$\chi_{q}(\delta) \propto \delta^{\tau(q)}$,

where $\tau(q)$ is the mass exponent of order $q$ which can be obtained by plotting the data of $\chi_{q}(\delta)$ and $\delta$ on log-log diagrams as the limit when $\delta \rightarrow \mathrm{w}$. Directly from the mass exponent $\tau(q)$ and the order $q$, the generalized multifractal dimensions can be expressed as:

$D(q)=\frac{\tau(q)}{1-q} \quad(q \neq 1)$,

when $q=1$ the information dimension, $D(1)$, is obtained as following:

$D(1)=\lim _{r \rightarrow 0} \frac{\sum_{i=1}^{N(r)} \mu_{i}(\delta) \log \mu_{i}(\delta)}{\log r}$.

According to Eq. (5), the correlation dimension, $D(2)$, is obtained when $q=2$.

The generalized multifractal spectrum function, $f(\alpha)$, can then be calculated through Legendre transform (Evertsz and Mandelbrot, 1992):

$f(\alpha(q))=\alpha(q) q-\tau(q)$,

where the so-called singularity exponent, $\alpha(q)$, can be effectively deduced by $\alpha(q)=\partial \tau(q) / \partial q$. For multifractal distribution patterns, the spectrum $f(\alpha)$ has a concave downward curvature with $\alpha$-values falling into a range. In case of single fractal distribution measures, $\alpha(q)$ will remain the same for all the boxes of the same sizes covering the metallic particle, and the multifractal spectrum $f(\alpha)$ will be a single point. Anyway, when $q=0$, the $f(\alpha)$ value will reach the maximum and the corresponding value is the box-counting dimension $D(0)$.

In many works, the main multifractality properties have also been described by several parameters derived from $D(q)$ 
Table 2. Average $D_{A P}$ values of the pyrrhotite particles from the seven basalt samples.

\begin{tabular}{llllllll}
\hline & 1 & 2 & 3 & 4 & 5 & 6 & 7 \\
\hline$D_{A P}$ & 1.3576 & 1.2591 & 1.5639 & 1.3632 & 1.3414 & 1.4878 & 1.3035 \\
\hline
\end{tabular}
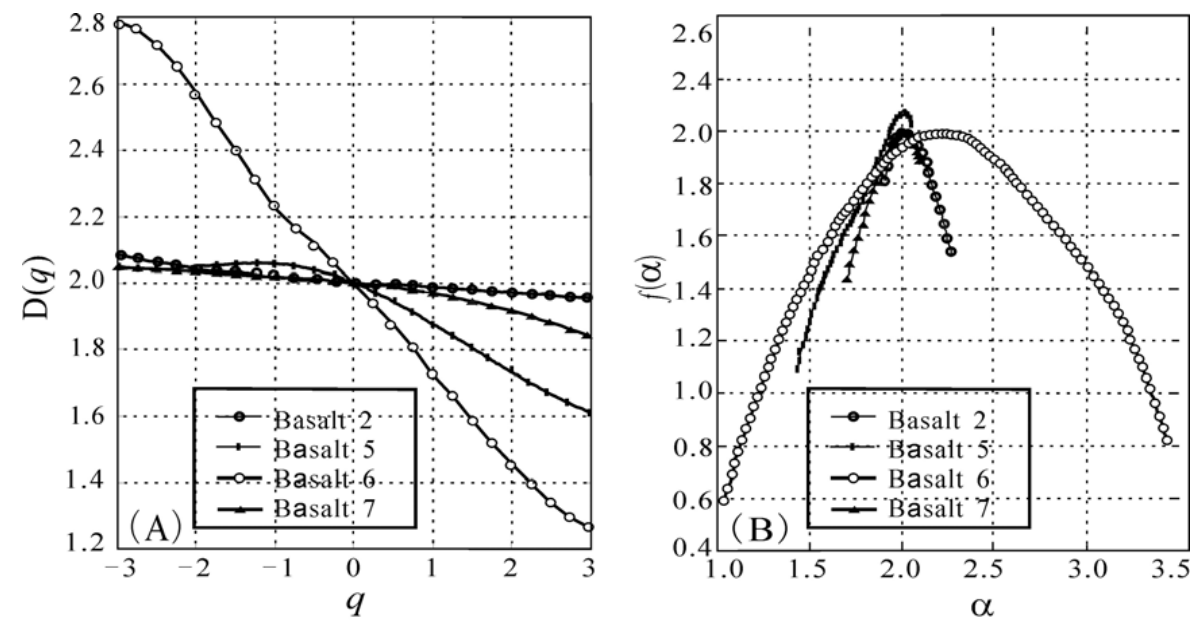

Fig. 3. Multifractal analysis results. (a) Estimation of the spectra of generalized fractal dimensions when $-3<q<3$ for the mineral distribution patterns in the thin sections from the basalt samples of the second, the fifth, the sixth and the seventh segment, respectively. The $D(q)$ in the calculated spectra have been obtained with regression fits where the determination coefficient $R^{2}$ is higher than 0.955 . (b) Multifractal spectra for the spatial distribution patterns of pyrrhotite particles.

and $\tau(q)$ (Tarquis et al., 2006; Vidal et al., 2008; Cheng, 1999; Xie et al., 2010b).

In homogeneous structures, $D q$ are close to one another, whereas for a monofractal structure they are equal. A difference, $w=D(-10)-D(10)$, was defined as the width of the multifractal spectra and suggested to be an important predictive parameter (Tarquis et al., 2006). A greater $w$ means a wider spectrum and a more heterogeneous distribution of the spatial structures (Muller et al., 1995; Vidal et al., 2006). In the same way, the widths of the multifractal spectra, $w=D(-3)-D(3)$ and $w=D(0)-D(2)$, are also defined here to characterize the multifractality of the distribution of the pyrrohite particles in this study.

The properties of the function of the mass exponent $\tau(q)$, have also been found to be useful for describing multifractality (Cheng, 1999). Represented by $\tau "(1)=\tau(2)-2 \tau(1)+$ $\tau(0)$, the multifractality index (MI) is calculated and proved to be associated with spatial analysis parameters (Cheng, 1999).

For each image of the studied metallic mineral particles, we calculate the multifractal parameters of all the mineral particles with $q$ ranging from -3 to 3 in increments of 0.2 to construct the partition function $\chi_{q}(\delta)$. With standard errors less than 0.075 , Fig. $3 \mathrm{a}$ is the plot of the generalized fractal dimensions $D(q)$ vs the moment $q$ for the images from Segment 2, 5, 6 and 7, respectively. It can be seen clearly that all the $D(q)-q$ plots are relatively smooth, with some fluctuating while others are constrained to a limited range.

Figure $3 b$ is the multifractal spectrum curves for the pyrrhotite particles at microscales in basalt samples. It shows that the multifractal spectrum curves are continuous and fluctuate in a relatively broad range, which presents the inhomogeneous distribution patterns of the pyrrhotite particles.

Eight fractal and multifractal parameters have been calculated to characterize the spatial distribution patterns of the pyrrhotites for all the 28 basalt digital images and the average values for each basalt segment have been listed in Table 3. These parameters shown in Table 3 can discern the spatial invariance of the pyrrhotite particles. It is clearly observed that $D(0)>D(1)>D(2)$, which implies that the distribution patterns of the pyrrhotite particles have a tendency to multifractality (Vidal et al., 2008). As Table 3 shows, for Segment 2 , the values of the information dimension $D(1)$ and the correlation dimension $D(1)$ reach a maximum, while the range of $D(q), \Delta\left(D\left(q_{\min }\right)-D\left(q_{\max }\right)\right)$, reaches a minimum. The multifractality index of Segment 2 is also the minimum. In this aspect, with the weakest multifractality, the pyrrhotite particles in Segment 2 distribute relatively homogeneously, but the pyrrhotites in other segments are more irregularly distributed in microspace. 
Table 3. Multifractal parameters for characterizing the spatial structures of the pyrrhotite particles' areas.

\begin{tabular}{llllllll}
\hline Basalt segment & 1 & 2 & 3 & 4 & 5 & 6 & 7 \\
\hline$D(-3)$ & 2.1198 & 2.0552 & 2.2328 & 2.1240 & 2.0556 & 2.2419 & 2.0996 \\
$D(3)$ & 1.6896 & 1.8723 & 1.3596 & 1.5728 & 1.7988 & 1.6711 & 1.8093 \\
$D(0)$ & 2.0000 & 2.0000 & 2.0000 & 2.0000 & 2.0000 & 2.0000 & 2.0000 \\
$D(1)$ & 1.8906 & 1.9527 & 1.7984 & 1.8578 & 1.9497 & 1.9068 & 1.9546 \\
$D(2)$ & 1.7657 & 1.9036 & 1.5499 & 1.6889 & 1.8807 & 1.7916 & 1.8993 \\
$\Delta(D(0)-D(2))$ & 0.2343 & 0.0964 & 0.4501 & 0.3111 & 0.1193 & 0.2084 & 0.1007 \\
$\Delta(D(-3)-D(3))$ & 0.4301 & 0.1830 & 0.8732 & 0.5512 & 0.2568 & 0.5708 & 0.2903 \\
Multifractality & -0.1808 & -0.0783 & -0.3666 & -0.2460 & -0.1143 & -0.2009 & -0.1186 \\
\hline
\end{tabular}

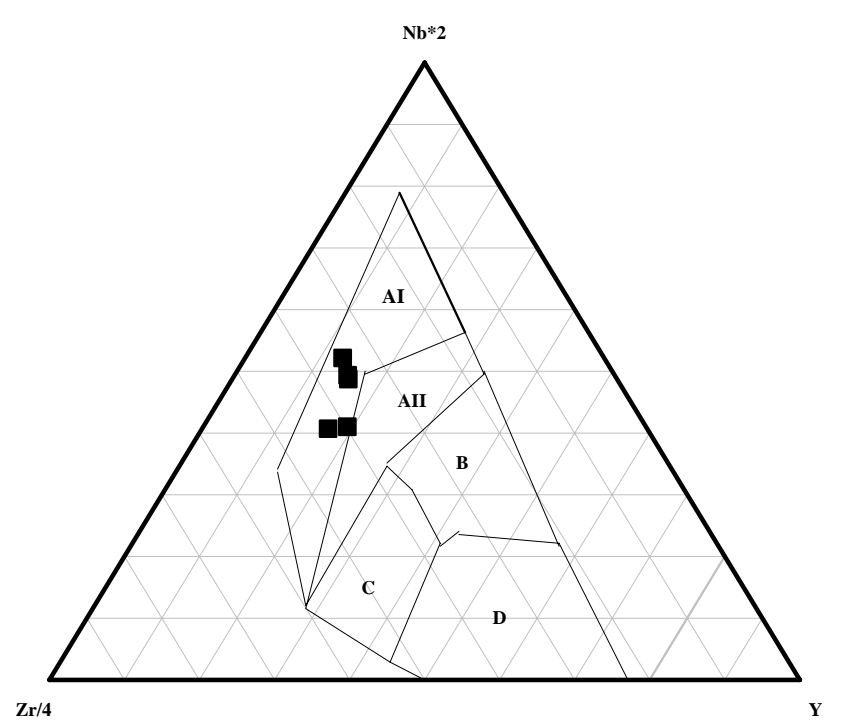

Fig. 4. Discrimination Nb-Zr-Y diagram (Meschede, 1986) for basalts from the four segments. (AI, AII = fields of intraplate alkali basalts; AII, C = fields of intraplate tholeiites; $\mathrm{B}=$ field of P-type MORB; D = field of N-type MORB; C, D = fields of volcanic arc basalts.)

\section{Petrological trace element analysis}

The concentrations analyzed by LA-ICP-MS in Table 4 are used to test the petrological characteristics of these samples in an attempt to demonstrate the difference exists in the spatial microstructure.

Firstly, high field strength elements (HFSEs) and rare earth elements (REEs), which are relatively immobile under altered and metamorphosed conditions, are used herein for distinguishing samples into tectonic settings. As shown in Fig. 4, the discrimination Nb-Zr-Y diagram (Meschede, 1986) reflects well that all the five samples fall into the field of intraplate alkali basalts, which shows that these samples originate from similar tectonic sources. It should be noted that there seems to be only four dots in Fig. 4. Actually, the dots representing Sample 201-3 and Sample 201-4 are close to each other.

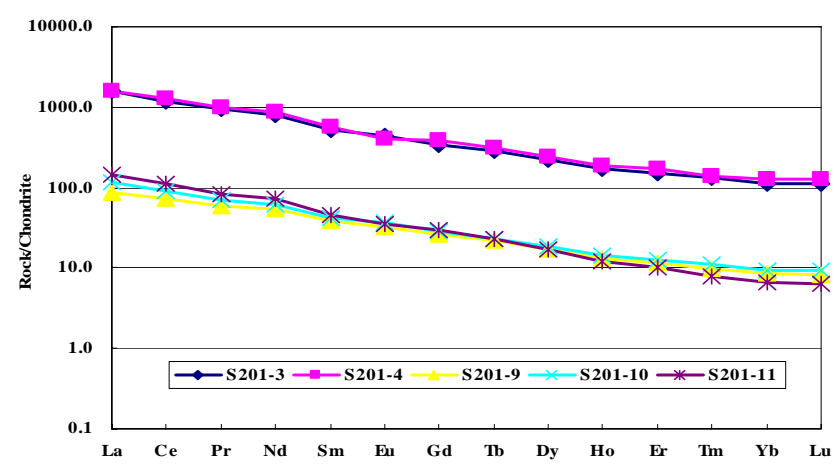

Fig. 5. Chondrite-normalized REE distribution patterns. (Normalizing values from Sun and Mc Donough, 1989.)

Figure 5 does show the Chondrite-normalized REE distribution patterns. It can be seen that all the samples show slightly sloping chondrite-normalized REE patterns, rich in light rare earth elements (LREE, La-Sm) but depleted in heavy rare earth elements (HREE, Eu-Lu), with $\left((\mathrm{La})_{N} /(\mathrm{Yb})_{N}\right.$ values ranging from 7.1 to 21.5. Samples 2014 and 201-11 have weakly negative Eu anomalies. The REE distribution patterns of samples 201-3 and 201-4 are similar to each other and their total REE contents are $1883.38 \mathrm{ppb}$ and $1973.74 \mathrm{ppb}$, respectively, and higher than those of other samples raging from 118.17 to167.92 ppb.

Figure 6 is the spider diagram of primitive mantlenormalized trace element concentrations. In Fig. 6, both the samples 201-3 and 201-4 show identical patterns with incompatible elements enriched, but high field strength elements (HFSEs, $U$ and Th) and heavy rare earth elements (HREE, Eu-Lu) of these two samples are relatively depleted. However, the samples 201-9, 201-10 and 201-11 are different from the above two samples.

In this aspect, the geochemical characteristics of the basalt samples from Segment 2 are quite different from those from Segments 5, 6 and 7. For the samples from Segment 5, 6 and 7 , the basalts are relatively enriched with large ion lithophile elements $(\mathrm{Rb}, \mathrm{Sr}, \mathrm{Pb})$ and HFSEs ( $\mathrm{U}$ and $\mathrm{Th}$ ), and show strong negative $\mathrm{Ba}$ and positive $\mathrm{Pb}$ anomalies, indicating an 


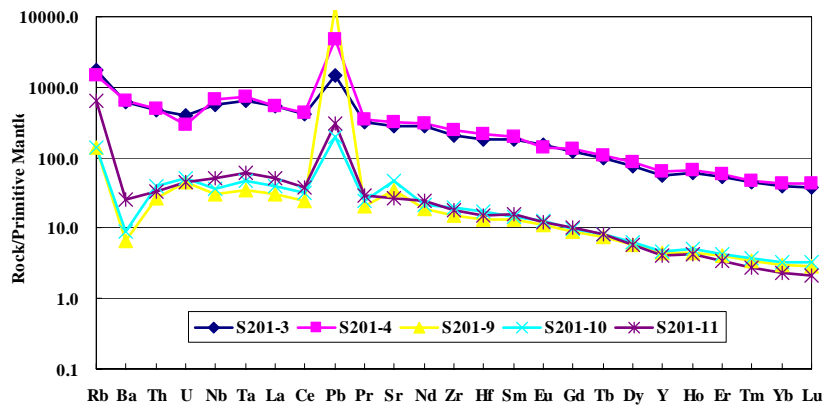

Fig. 6. Spider diagrams of Primitive mantle-normalized trace element concentrations. (Normalizing values from Sun and Mc Donough, 1989.)

affinity with continental crust. But for the basalt samples of Segment 2, neither are the Ba anomalies negative on the spider diagrams, nor are the $U$ values enriched in the samples 201-3 and 201-4.

\section{Conclusions}

We chose different basalt samples from different segments in Gejiu area to make thin sections, then acquired images under the Environmental Scanning Electron Microscope (ESEM), and measured their basic physical parameters of the pyrrhotite particles. The perimeters and areas of the pyrrhotites were obtained by digital image processing. P-A fractal model and the method of moments were used to inquire the microstructure of the pyrrhotite particles. Together with the bulk-rock trace element analysis, several conclusions can be reached:

1. For all the basalt samples, the pyrrhotite particles at the microscale level exhibit fractal and multifractal behaviors. The P-A fractal analysis shows that the areas and the perimeters of the pyrrhotite particles follow a powerlaw relationship and the $D_{A P}$ value of the pyrrhotite particles in the second basalt segment is smaller than those in other basalt segments. The multifractal analysis indicates well that the multifractal parameters of the pyrrhotite particles of the second basalt sample are quite different from other samples, and the multifractality of the spatial distribution patterns of the pyrrhotites at microscales are weaker than those from other basalt segments. The bulk-rock trace element analysis also distinguishes the basalt segment 2 from other basalt segments.

2. The rocks from different origins may have different micro-structures, which could result in different mineral structures at the microscale level. In other words, the spatial micro-structural complexity of the mineral particles may be closely related to the inherent microstructures of the wallrocks. In this perspective, fractal and
Table 4. Concentrations $\left(10^{-9}\right)$ of the trace elements from the basalt samples.

\begin{tabular}{|c|c|c|c|c|c|}
\hline Element & S201-3 & S201-4 & S201-9 & S201-10 & S201-11 \\
\hline $\mathrm{Be}$ & 15.3 & 21.4 & 2.58 & 6.62 & 3.31 \\
\hline $\mathrm{Sc}$ & 220 & 242 & 15.1 & 15.7 & 13.7 \\
\hline V & 2292 & 2596 & 199 & 192 & 213 \\
\hline $\mathrm{Cr}$ & 2702 & 1927 & 218 & 259 & 105 \\
\hline $\mathrm{Co}$ & 513 & 469 & 47.3 & 32.1 & 52.2 \\
\hline $\mathrm{Ni}$ & 1543 & 1091 & 173 & 102 & 92.2 \\
\hline $\mathrm{Cu}$ & 91.9 & 74.7 & 154 & 75.6 & 199 \\
\hline $\mathrm{Zn}$ & 1362 & 1317 & 132 & 130 & 229 \\
\hline $\mathrm{Ga}$ & 214 & 216 & 18.0 & 19.9 & 24.8 \\
\hline $\mathrm{Rb}$ & 1134 & 934 & 87.0 & 89.0 & 405 \\
\hline $\mathrm{Sr}$ & 5915 & 6843 & 713 & 1004 & 553 \\
\hline $\mathrm{Y}$ & 252 & 287 & 20.0 & 21.3 & 18.4 \\
\hline $\mathrm{Zr}$ & 2334 & 2712 & 165 & 216 & 197 \\
\hline $\mathrm{Nb}$ & 398 & 470 & 21.3 & 25.9 & 36.9 \\
\hline $\mathrm{Sn}$ & 79.1 & 104 & 223 & 416 & 228 \\
\hline $\mathrm{Cs}$ & 1017 & 696 & 64.2 & 65.2 & 94.8 \\
\hline $\mathrm{Ba}$ & 4335 & 4447 & 45.9 & 62.5 & 174 \\
\hline $\mathrm{La}$ & 376 & 371 & 20.6 & 27.3 & 34.5 \\
\hline $\mathrm{Ce}$ & 732 & 771 & 44.2 & 55.0 & 67.6 \\
\hline $\operatorname{Pr}$ & 89.0 & 95.7 & 5.65 & 6.73 & 7.98 \\
\hline $\mathrm{Nd}$ & 381 & 407 & 25.0 & 28.9 & 33.6 \\
\hline $\mathrm{Sm}$ & 80.9 & 87.1 & 5.88 & 6.42 & 6.97 \\
\hline $\mathrm{Eu}$ & 25.5 & 23.4 & 1.87 & 2.12 & 2.06 \\
\hline $\mathrm{Gd}$ & 71.4 & 78.2 & 5.36 & 5.75 & 6.16 \\
\hline $\mathrm{Tb}$ & 10.5 & 11.8 & 0.82 & 0.88 & 0.87 \\
\hline Dy & 56.2 & 62.6 & 4.34 & 4.67 & 4.31 \\
\hline Ho & 9.81 & 10.8 & 0.74 & 0.81 & 0.69 \\
\hline $\mathrm{Er}$ & 25.4 & 27.9 & 1.93 & 2.06 & 1.67 \\
\hline $\mathrm{Tm}$ & 3.36 & 3.51 & 0.25 & 0.28 & 0.20 \\
\hline $\mathrm{Yb}$ & 19.4 & 21.3 & 1.45 & 1.58 & 1.15 \\
\hline $\mathrm{Lu}$ & 2.82 & 3.18 & 0.21 & 0.24 & 0.16 \\
\hline $\mathrm{Hf}$ & 57.1 & 66.4 & 4.06 & 5.35 & 4.73 \\
\hline $\mathrm{Ta}$ & 26.6 & 29.9 & 1.44 & 1.89 & 2.47 \\
\hline $\mathrm{Tl}$ & 28.3 & 30.5 & 0.76 & 0.57 & 3.94 \\
\hline $\mathrm{Pb}$ & 105 & 338 & 1021 & 13.8 & 21.4 \\
\hline Th & 40.1 & 41.9 & 2.25 & 3.27 & 2.85 \\
\hline $\mathrm{U}$ & 8.42 & 6.09 & 0.94 & 1.09 & 0.94 \\
\hline
\end{tabular}

multifractal may provide new information on the genesis conditions of ore crystals since different genetic conditions could result in different spatial structures of minerals in space.

Acknowledgements. This research has been financially supported by a Distinguished Young Researcher Grant (40525009), a HighTech Research and Development Grant (2006AA06Z115) by the Ministry of Science and Technology of China, and a Strategic Research Grant (40638041) and two other Natural Science Grants (40872195 and 40525009) awarded by the Natural Science Foundation of China. The authors are extremely grateful to J. Lu and P. Xiao at China University of Geosciences in Wuhan for their help during the preparation of thin sections. And all the field work had 
been supported with the help of Tin-company in Yunnan Province, China. The concentrations of trace elements were measured in the state key lab of Geological Processes and Mineral Resources at China University of Geosciences with the help of Y. Liu.

Edited by: S. Lovejoy

Reviewed by: F. Agterberg and two other anonymous referees

\section{References}

Agterberg, F. P., Cheng, Q., Brown, A., and Good, D.: Multifractal modeling of fractures in the Lac du Bonnet Batholith, Manitoba, Computers and Geosciences, 22(5), 497-507, 1996.

Bird, N., Diaz, C. M., Saa, A., and Tarquis, M.: Fractal and multifractal analysis of pore-scale images of soil, J. Hydrol., 322, 211-219, 2006.

Cheng, Q., Agterberg, F. P., and Ballantyne, S. B.: The separation of geochemical anomalies for background by fractal methods, Journal of Geochemical Exploration, 51, 109-130, 1994.

Cheng, Q.: The perimeter-Area Fractal Model and Its Application to Geology, Mathematical Geology, 27, 69-82, 1995.

Cheng, Q.: Multifractality and spatial statistics, Computers and Geosciences, 25(9), 949-961, 1999.

Cheng, Q.: Mapping singularities with stream sediment geochemical data for prediction of undiscovered mineral deposits in Gejiu, Yunnan Province, China, Ore Geology Reviews, 32(1-2), 314324, 2007.

Evertsz, C. J. G. and Mandelbrot, B. B.: Multifractal measures (Appendix B) [A]. In: Peitgen H-O, Jurgens H, Saupe D, eds. Chaos and fractals[C]. New York: Springer Verlag, 922-953, 1992.

Flavio, S. A., Stefan, L., and Gregor, P. E.: Quantitative Characterization of Carbonate Pore Systems By Digital Image Analysis, AAPG Bulletin, 82(10), 1815-1836, 1998.

Gerard, R. E., Philipson, C. A., Manni, F. M., and Marshall, D. M.: Petrographic image analysis: and alternate method for determining petrophysical properties, in: Automated pattern analysis in petroleum exploration: New York, edited by: Palaz, I. and Sengupta, S. K., Springer Verlag, 249-263, 1992.

Hakon, W.: Volume, Shape, and Roundness of Rock Particles, J. Geol., 40(5), 443-451, 1932.

Halsey, T. C., Jensen, M. H., and Kadanoff, L. P.: Fractal measures and their singularities - the characterization of strange sets. Physical Review A 33(2), 1141-1151, 1986.

Krohn, C. E. and Thompson, A. H., Fractal sandstone pores: Automated measurements using scanning-electron-microscope images. Phys. Rev. B, 33, 6366-6374, 1986.

Li, Y., Qin, D., and Dang, Y.: Lithological Features of Basalt in Gejiu Eastern Area, Yunnan Province, Sci. Technol. Rev., 24(2), 70-72, 2006.

Li, Y., Qin, D., Dang, Y., Hong, T., and Yan, Y.: The distribution of the Indo-Chinese basalts in time and space in the eastern Gejiu, Journal of Chengdu university of Technology, 34(1), 2328, 2007.

Liu, Y., Hu, Z., Gao, S., Günther, D., Xu, J., Gao, C., and Chen, H.: In situ analysis of major and trace elements of anhydrous minerals by LA-ICP-MS without applying an internal standard, Chemical Geology, 257, 34-43, 2008.
Lovejoy, S.: Area-perimeter relation for rain and cloud areas, Science, 216(4542):185-187, 1982.

Mandelbrot, B. B.: Fractals: form, chance, and dimension, Freeman, San Francisco, 1977.

Mandelbrot, B. B.: The fractal geometry of nature (updated and augmented edition), Freeman, New York, 1983.

McCauley, J. L.: Models of permeability and conductivity of porous media, Physica A, 187, 18-54,1992.

Meschede, M.: A method of discriminating between different types of mid-ocean ridge basalts and continental tholeiite with the $\mathrm{Nb}$ Zr-Y diagram, Chemical Geology, 56, 207-218, 1986.

Muller, J. and McCauley, J. L.: Implication of fractal geometry for fluid flow properties of sedimentary rocks. Transp. Porous Media, 8, 133-147, 1992.

Muller, J., Huseby K. O., and Saucier A.: Influence of Multifractal scaling of pore geometry on permeabilities of sedimentary rocks. Chaos, Solitons and Fractals, 5(8), 1485-1492, 1995.

Muller, J.: Characterization of pore space in chalk by multifractal analysis, J. Hydrol., 187, 215-222, 1996.

Pachepsky, Y., Crawford, J. W., and Rawls W. J.: Fractals in soil science: Developments in Soil Science, Elsevier Science, Amsterdam, Hardbound, 2000.

Perrier, E., Bird, N., and Rieu, M.: Generalizing the fractal model of soil structure: the pore-solid fractal approach, Geoderma, 88(34), 137-164, 1999.

Sun, S. S. and McDonough, W. F.: Chemical and isotopic systematics of oceanic basalts: implications for mantle composition and processes, in: Magmatism in Ocean Basins, edited by: Saunders, A. D. and Norry, M. J., Geol. Soc. Spec. Publ., London, 313-345, 1989.

Tarquis, A. M., McInnes, K. J., Key, J. R., Saa, A., García, M. R., and Díaz, M. C.: Multiscaling analysis in a structured clay soil using 2D images, J. Hydrol., 322(1-4), 236-246, 2006.

Vidal Vázquez, E., García Moreno, R., Miranda, J. G. V., Díaz, M. C., SaŔequejo, A., Paz Ferreiro, J., and Tarquis, A. M.: Assessing soil surface roughness decay during simulated rainfall by multifractal analysis, Nonlin. Processes Geophys., 15, 457-468, doi:10.5194/npg-15-457-2008, 2008.

Wadell, H.: Volume, shape and roundness of rock particles, J. Geol., 40, 443-451, 1932

Wang, Z., Cheng, Q., and Xia, Q.: The P-A fractal model characterizing microstructure of minerals, Proceedings of IAMG'05: GIS and Spatial Analysis, 317-322, 2005.

Wang, Z.: GIS-Based Fractal/multifractal modeling of texture in mylonites and banded sphalerite ores, Ph.D dissertation in the Department of Earth and Space Science and Engineering, York University, Canada, 2008.

Xie, S., Cheng, Q., Li, Z., Xing, X., and Chen, S.: Assessing Microstructures of Ore-minerals by multifractal, Earth Science - Journal of China University of Geosciences, 34(2), 263-269, 2009.

Xie, S., Cheng, Q., Ling, Q., Li, B., Bao, Z., and Fan, P.: Fractal and Multifractal Analysis of Carbonate Pore-scale Digital Images of Petroleum Reservoirs, Marine and Petroleum Geology, 27, 476485, 2010a.

Xie, S., Cheng, Q., Xing, X., Bao, Z., and Chen, Z.: Geochemical multifractal distribution patterns in sediments from ordered streams, Geoderma, doi:10.1016/j.geoderma.2010.01.009, in press, $2010 \mathrm{~b}$. 
Yu, C. W., Tang Y. J., and Shi P. F.: The Dynamic System of Polymetallic Metallogenic Province in Gejiu, Yunnan, Wuhan: Publishing House of China University of Geosciences, 394, 394 pp., 1988.

Zhang, Z., Mao, H., and Cheng, Q.: Fractal Geometry of Element Distribution on Mineral Surfaces, Mathematical Geology, 33(2), 217-228, 2001.
Zhijun Chen, Qiuming Cheng, Jiaoguo Chen, and Shuyun Xie: A novel iterative approach for mapping local singularities from geochemical data, Nonlin. Processes Geophys., 14, 317-324, doi:10.5194/npg-14-317-2007, 2007.

Zuo, R., Cheng, Q., Xia, Q., and Agterberg, F. P.: Application of Fractal Models to distinguish between different mineral phases, Mathematical Geosciences, 41, 71-80, 2009. 